\title{
Politics, primary healthcare and health: was Virchow right?
}

\author{
$\sqrt{ }$ Barbara Starfield* \\ EDITOR'S \\ CHOICE
}

In this issue of JECH, authors from both the People's Health Movement ${ }^{1}$ and $\mathrm{WHO}^{2}$ agree that primary healthcare makes a considerable contribution to reducing the adverse impact of social inequalities on health. That is, primary healthcare is a 'health equity-producing' social policy. Both groups of authors agree that health systems do not exist in isolation from other social systems. Both provide examples of how the market orientation of neo-liberal globalisation has worked against improvements in general and equity in health specifically. The role of world trade agreements in compromising nutritional status of socially disadvantaged populations provides a powerful case for the importance of inter-sectoral approaches in health policy activities.

Both papers speak of 'primary health care' rather than of 'primary care'. The distinction between the two is at the heart of achieving greater equity in health through societal actions. Both clinical practices and system policies need consideration. ${ }^{3}$ The literature on 'primary care' is largely clinical, having to do with the behaviour of health services professionals and their interactions with people and, increasingly, the subpopulations for whom they provide services. Within the last two decades there has been increasing clarity about which 'behaviours' are most important to adequacy of primary care: first contact accessibility and use, identification with a regular source of care that is person (rather than disease) focused care over time, comprehensiveness of services available and provided, and coordination (when care from other places is required). These characteristics, all amenable to assessment in reliable and valid ways, are now so well-known that tools for their

\footnotetext{
*Editors' note Just as this issue was going to press, we learned that Barbara Starfield MD, MPH, died suddenly and unexpectedly while swimming. Dr Starfield was a world-renowned scholar and tireless advocate for primary care and health inequalities research. She made an enormous impact in both of these fields and her contributions will be greatly missed by our research community. We thank Normalie Barton for checking the proofs on behalf of Dr Starfield.
}

assessment are rapidly being adopted in many different places around the world. ${ }^{4}$

International comparisons demonstrate that good clinical primary care depends on good primary healthcare-that is, on specific health system policies for population. Critical among these policies are attempts to distribute resources equitably-that is, according to need; 'progressive' (as distinguished from 'regressive') financing under government control or regulation; low or no cost sharing for primary care services; and breadth of services available (comprehensiveness) within the primary care sector. ${ }^{35}$ Each of these policy characteristics reflects more general system characteristics: focus on distribution of health characteristics in the population-that is, an equity focus rather than just on average levels; progressivity of financing of social services in general; and consideration of population needs rather than demands (which favour the more powerful rather than the disenfranchised). That is, societies that are more equitable tend to be more equitable in many regards, ${ }^{6}$ because progressive governments generally promote more progressive policies across a range of social sectors

Primary healthcare-oriented health systems have been shown to be generally more effective in achieving better health (particularly at young ages) at lower costs than is the case for systems more oriented to disease management and specialty care. It is not often recognised that they have more equitable distributions of health as well. Even in the USA, one of the most inequitable societies in the industrialised world, better primary care resources preferentially improve health more in socially disadvantaged populations than in the majority population. ${ }^{7}$ A comparison of age adjusted survival from breast cancer in Canada (which has a health system more oriented towards primary care than in the USA) showed a strong socioeconomic gradient in survival from breast cancer in the USA but not in Canada and demonstrated that the survival advantage in cancer is present in low-income areas only and that it is less in women over the age of
65 years (because of the primary care enhancing impact of universal financial coverage of women over the age of 65 years in the USA). ${ }^{8}$ After primary care reform was initiated in Thailand in the early 1990s, there was marked improvement in both the rate ratio and absolute differences in under-5 mortality across income quintiles. ${ }^{9}$ In Ontario, Canada, populations in areas with greater primary care physician supply have better experiences with a wide variety of healthcare access and outcome indicators-even more so in lower income areas than in higher income ones. ${ }^{10}$

Primary care is equity-producing because its functions, separately and in combination, facilitate the achievement of equity in health. ${ }^{7}$ Greater comprehensiveness of services better meets the needs of populations that have a greater burden of morbidity burdens as a result of more comorbidity. Person-focused care over time provides better knowledge of patients and better recognition of their health problems and their genesis. Greater accessibility of services and first-contact care facilitate more timely care. Better coordination of care facilitates adequate care for people whose limited material resources are a barrier to their ability to navigate the health system. Better person-focused care increased the likelihood of achieving greater overall resilience in dealing with threats to health (which are always greater among populations with fewer material resources).

If primary care is equity producing, and if good primary care requires supportive health policies (that is, good primary healthcare), the importance of intersectoral linkages at all levels of care needs recognition and proactive advocacy. Virchow's notion that 'medicine is a social science and politics is nothing more than medicine on a grand scale ${ }^{11}$ implies that promotion of equity-enhancing health policies need not wait for revolutions or total societal change. They can and should be an important first step to more general appreciation of the benefits of more equitable policies in other sectors as well as in health. Lessons from healthcare reform in these directions can have spillover effects particularly in times of social stress across the countries of the world. ${ }^{12}$ If there ever was a time of worldwide economic stress, it is now-an opportunity made even more potent with the recent publication by the WHO of its two landmark publications on societal determinants and on primary care. $^{1314}$

Even the best evidence and most consistent public support fails to change 
policies when interests in maintaining the status quo have the power to thwart change. There are many barriers to changes in health policy particularly when special interests have become entrenched. Nowhere is this more evident than in the USA, where both knowledge and public opinion favour giving people more choice in a government (instead of a private) insurance option. Because many legislators are heavily funded for re-election campaigns by private insurance companies, these options have (so far) failed to reach representation in proposed legislation and, thus, working against an important aspect of primary care policy: equitable resource distribution and progressive and government-regulated financing. Even international health organisations adopt policies that are ultimately (and possibly inadvertently) anti-equity. For example, although it is certainly true that cause of death is increasingly attributed to chronic illness and that rates of diagnosis of specific chronic illnesses are increasing, it does not follow that health systems should be re-oriented around the management of chronic illness. As acute illnesses are better treated so that rapid death is avoided, deaths will increasingly be attributed to chronic problems so that, ultimately, all deaths should be associated with chronic illness. Moreover, a focus on chronic illness detracts from attention to acute problems throughout the life course that make people vulnerable to chronic illness. Thus, the focus on chronic illness disadvantages children-at least relatively if not also absolutely. Additionally, the focus on chronic illness has been manifested by a preoccupation with specific chronic illnesses, particularly those that result in placing people on lifelong medication (with its attendant dangers of unintended adverse events). Guidelines, and hence decision support systems, for the management of these selected few conditions do not take co-morbidity into account and are, therefore, much less relevant in primary care than in specialty care. ${ }^{15}$ As socially disadvantaged populations and subpopulations have higher morbidity burdens, the application of disease-oriented guidelines is particularly hazardous to them. Eliminating or controlling diseases one-by-one is not likely to materially reduce the chances of another, particularly in socially vulnerable populations. It may also be unconscionable when the most serious shortfalls in achieving the Millennium Development goals are in maternal and child health. Care focused on particular diseases runs the risk of reinventing the now discredited 'selective' primary care programmes of the post World War II period. When particular diseases are the focus of policy attention, interests that are vested in those diseases (either from the viewpoint of their potential for profit from medications or technology or from the personal predilections of wealthy donors) often are responsible for diverting resources from health problems that are most important in socially vulnerable populations. It is of great interest that the equity-focused health agenda in Norway specifically excludes a focus on particular diseases or types of diseases. ${ }^{16}$

Continued reliance on information systems based on the outmoded International Classification of Diseases is also likely to work against the person-focus of primary healthcare. Diseases are changing. Classifications based originally on the observations of coroners need to be replaced with categorisations that recognise that there are probably only a few types of mechanisms of illness generation: infections, external injuries, developmental abnormalities, genetic susceptibilities, autoimmune defects and cellular degeneration. For example, most chronic diseases are now thought to be infectious in origin. ${ }^{17}$ The organ-system based nature of the International Classification of Diseases fostered the development of disease-oriented specialties and works against the fundamental primary care principle of addressing people's needs instead of professionally defined priorities. Refocusing health services requires a new way of focusing on illnesses and their antecedents and recognising that most diseases are inter-related. The example of chronic obstructive pulmonary disease is instructive; it is now recognised as an illness with various systemic manifestations rather than a respiratory disorder. ${ }^{18}$ True patient-centered care requires attending to the needs of patients rather than to the priorities of professionals or to the demands of the socially advantaged whose power gives them the greatest influence on health services priorities. As a start, payment for performance schemes should be based at least in part on improvement in health as judged by patients (which will reflect unintended adverse effects as well as intended ones) as professional criteria have so far not recognised the importance of incorporating recognition and coding of patients' problems in quality assurance activities.

None of these changes in health services, or in primary care, will occur without a much stronger role in development of health policies at state, provincial or local levels. A succession of advances in the understanding of illness genesis and progression started over 150 years ago with social medicine. Social medicine recognises that characteristics relating to the organisation of society and the interactions of people have a powerful impact on 'causation' of illness in individuals. Later on, community medicine-the need for health services organised around community needs-was popularised by the work of the Karks and based on their work in South Africa. ${ }^{19}$ For example, modern-day community-based prevention efforts can eliminate the corporate promotion of calorie-dense, nutrient-poor food and, thus, reduce community rates of obesity. ${ }^{20}$ The Commission on Social Determinants of Health went further in recognising the role of policy makers in creating the conditions for health and eliminating the conditions for poor health. But, ultimately, it is societal politics that are the determinants of those policies that count. Health is a strong individual and societal priority; equity in health is not a controversial goal, at least in principle, in most places. Governments now have the knowledge base to justify strong planning efforts and/or strong regulation of transnational corporations, financial and trade organisations, and other private players to assure that primary care principles are translated into strong primary care; political activity on the part of populations (as is occurring even in the USA) must not allow these goals to be thwarted. ${ }^{21}$

Primary care, which has conventionally been considered a clinical discipline, is rapidly becoming a population-oriented discipline (primary healthcare) if for no other reason than that integrated health systems require the definition of a population. Recognition of the inter-relationships between health policy and, even broader, social policy, is not far behind. Societal policies that are equity-producing are an imperative and there is no better starting place than in the health arena. The articles by Sanders et al and Rasanathan et al are on target in setting the stage for a re-evaluation of the role of health systems in dealing with population health needs in the context of other needs. Healthcare reform is societal and political reform, as Virchow recognised.

\section{Competing interests None declared.}

Provenance and peer review Commissioned; not externally peer reviewed.

J Epidemiol Community Health 2011;65:653-655. doi:10.1136/jech.2009.102780 


\section{REFERENCES}

1. Sanders D, Baum FE, Benos A, et al. Revitalising primary healthcare requires an equitable global economic system-now more than ever. J Epidemiol Community Health 2011;65:661-5

2. Rasanathan K, Montesinos EV, Matheson D, et al. Primary health care and the social determinants of health: essential and complementary approaches for reducing inequities in health. $\checkmark$ Epidemiol Community Health 2011;65:656-60.

3. Starfield B, Shi L. Policy relevant determinants of health: an international perspective. Health Policy 2002;60:201-18.

4. Starfield B, Shi L. Primary Care Assessment Tools. http://www.jhsph.edu/pcpc/pca tools.html (accessed 31 May 2011).

5. Gilson L, Doherty J, Loewenson R, et al. Challenging Inequity through Health Systems. Final Report, Knowledge Network on Health Systems, June 2007. WHO Commission on the Social Determinants of Health. Johannesburg, South Africa: Centre for Health Policy, EQUINET, London School of Hygiene and Tropical Medicine, 2007. http://www.who.int/social determinants/resources/ csdh_media/hskn_final_2007_en.pdf (accessed 31 May 2011).
6. Wilkinson R, Pickett K. The Spirit Level: Why More Equal Societies Almost Always Do Better. London, UK: Allen Lane, 2009.

7. Starfield B, Shi L, Macinko J. Contribution of primary care to health systems and health. Milbank 0 2005:83:457-502.

8. Gorey KM. Breast cancer survival in Canada and the USA: meta-analytic evidence of a Canadian advantage in low-income areas. Int J Epidemiol 2009;38:1543-51.

9. Vapattanawong $\mathbf{P}$, Hogan $\mathrm{MC}$, Hanvoravongchai $\mathbf{P}$, et al. Reductions in child mortality levels and inequalities in Thailand: analysis of two censuses. Lancet 2007;369:850-5.

10. Guttmann A, Shipman SA, Lam K, et al. Primary care physician supply and children's health care use, access, and outcomes: findings from Canada. Pediatrics 2010;125:1119-26.

11. Virchow R. Die medizinische Reform. In: Sigerist $H E$, ed. Medicine and Human Welfare. New Haven, CT: Yale University Press, 1941

12. Runciman D. How messy it all is. London Review of Books 2009;31:3-6.

13. World Health Organization Commission on Social Determinants of Health. Closing the Gap in a Generation: Health Equity through Action on the Social Determinants of Health. Final Report of the Commission on Social Determinants of Health.
Geneva, Switzerland: World Health Organization, 2008. (http://whalibdoc.who.int/publications/2008/ 9789241563703_eng.pdf (accessed 31 May 2011).

14. World Health Organization. The World Health Report 2008: Primary Health Care-Now More than Ever. Geneva, Switzerland: World Health Organization, 2008

15. Stange KC. A science of connectedness. Ann Fam Med 2009:7:387-95.

16. Dahl E, Lie M. Policies to tackle health inequalities in Norway: from laggard to pioneer? Int J Health Serv 2009;39:509-23.

17. National Academy of Sciences. The Infectious Etiology of Chronic Diseases. Defining the Relationship, Enhancing the Research, and Mitigating the Effects. Washington, DC: National Academies Press, 2004.

18. Beasley R, Weatherall M, Travers J, et al. Time to define the disorders of the syndrome of COPD. Lancet 2009;374:670-2.

19. Kark SL. From medicine in the community to community medicine. JAMA 1974;228:1585-6.

20. Goodman A. President Obama's health plan and community-based prevention. Am J Public Health 2009:99:1736-8.

21. Birn AE. Making it politic(al): closing the gap in a generation: health equity through action on the social determinants of health. Soc Med 2009:4:166-82
Advancing Postgraduates. Enhancing Healthcare.

The Postgraduate Medical Journal is dedicated to advancing the understanding of postgraduate medical education and training. 